\section{The Royal College of Ophthalmologists' Cataract Surgery Commissioning Guidance: executive summary}

\section{Background}

The Royal College of Ophthalmologists recently published evidence-based guidance on commissioning for cataract surgery ${ }^{1}$ in response to reports of wide geographical variation in access to cataract surgery in England ${ }^{2-4}$ and the increasing use of arbitrary Snellen visual acuity thresholds to govern access to cataract surgery. ${ }^{2}$

This article summarises the main findings of the Commissioning Guidance and current issues surrounding cataract surgery provision in the NHS. The methodology used to develop this guidance was granted National Institute for Health and Care Excellence (NICE) accreditation in July 2015.

\section{Methodology}

The Cataract Surgery Commissioning Guidance was developed in accordance with the Royal College of Ophthalmologists Commissioning Guidance Process Manual. ${ }^{5}$ The Guideline Development Group reached consensus on the topics to be covered and the questions to be answered by the Guidance and a systematic search of the literature was undertaken to address these. Searches were made of the Cochrane Libraries, MEDLINE, EMBASE, NHS Evidence-guidelines, NHS Evidence-commissioning, National Guidelines Clearing House, Google and other grey literature including the Royal College of Ophthalmologists and College of Optometrists websites. The guidance does not apply to cataract surgery under the age of 18 years or that where the primary aim is correction of refractive error.

\section{Epidemiology and risk factors for cataract}

Cataract is the leading cause of blindness in the world. ${ }^{6}$ Cataract surgery is currently the only effective treatment to improve or maintain vision and is the most commonly performed elective surgical procedure in the UK with around 330000 cataract operations performed per year in England in recent years. ${ }^{7}$ The requirement for cataract surgery is anticipated to increase with increasing life expectancy and a growing population. ${ }^{8}$

There are no recent estimates for cataract surgery rates based on need. However, overall crude estimates based on current demand from Hospital Episode Statistics data suggests surgery incidence rates of $\sim 530$ per 100000 population or 3200 per 100000 for those over 65 years old per year in recent years (2011 data). ${ }^{9,10}$ Risk factors for cataract include increasing age, diabetes mellitus, corticosteroid use, female gender, socioeconomic status, ethnicity, smoking and alcohol. ${ }^{11,12}$ Some populations have a high prevalence of cataract; for example, $77 \%$ of British people aged 42 years old or more originating from the Indian subcontinent have cataract. $^{12}$

\section{Cataract surgery}

Cataract surgery is associated with improvements in visual acuity, contrast sensitivity, depth perception, activity, anxiety, depression, visual disability, confidence, handicap and quality of life and reduction in falls. ${ }^{13-15}$

Cataract surgery is generally reported to be highly cost effective ${ }^{16-19}$ and even in populations with mildly visually impairing cataract (baseline visual acuity $6 / 12$ or better in $75 \%$ patients) it is estimated to be cost effective with an incremental cost per quality adjusted life year of $£ 13172$ over an individual's lifetime (assuming an anticipated lifespan of 10 years following surgery). ${ }^{20}$ Overall cataract surgery is, for example, reported to be comparable to hip replacement in cost effectiveness. ${ }^{18}$

Approximately $40 \%$ patients undergo cataract surgery on both eyes. ${ }^{7,21}$ A systematic review ${ }^{22}$ funded by the National Institute for Health Research concluded that second eye cataract surgery was associated with a clinically meaningful improvement in stereopsis (depth perception), but did not affect other measures of visual acuity or visual function or health related quality of life, apart from an improvement in the mental health component of health related quality of life in one randomised controlled trial. Second eye cataract surgery was reported to be generally cost effective and the probability of cost effectiveness at willingness-to-pay thresholds of $£ 10000$ and $£ 20000$ was $100 \%$. A detailed analysis of patients who were unhappy with their vision after their first cataract operation found that anisometropia and cataract in the fellow eye accounted for more than a third of such cases. ${ }^{23}$

\section{Thresholds for cataract surgery}

Historically, 'cataract causing visual impairment' was defined as a visual acuity in one or both eyes poorer than $6 / 12$ where the impairment was attributable to lens opacity. ${ }^{24}$ This level is no longer considered an appropriate threshold for surgical intervention because of the need for higher visual function to maintain independence, including that for driving, rising patient expectations and advances in surgical technique. ${ }^{25}$

Significant improvements in visual symptoms and visual function may occur following cataract surgery even where the preoperative visual acuity is $6 / 6$ or better. However, the risk of worse visual acuity after surgery also increases where the preoperative visual acuity is very good, $7,21,26$ so surgery should be considered at this level of visual acuity only where the patient is experiencing significant symptoms attributable to cataract.

The Royal College of Ophthalmologists' National Ophthalmology Database shows that, for the period $2006-2010,3 \%, 5 \%$ and $36 \%$ of eyes undergoing cataract surgery have preoperative visual acuities of better than or equal to $0.00,0.18$ and $0.30 \log$ MAR respectively (equivalent to $6 / 6,6 / 9$ and $6 / 12$ Snellen) $)^{7}$ indicating that before restrictions on access to cataract surgery based on visual acuity were commonplace, eyes with $6 / 9$ or better preoperative visual acuities accounted for only 1 in every 20 cataract surgeries.

Although visual acuity remains a useful component of the assessment of visual disability from cataract, cataract surgery should be considered in the first eye or second eye of a patient who has disabling visual symptoms attributable to cataract. For instance, a patient 
who experiences disabling glare due to cataract when driving may still achieve a visual acuity of better than 6/9 under ideal conditions of illumination.

In patients with learning disability or cognitive impairment for other reasons, it may not be possible to measure visual acuity, and in this situation, clinicians will need to base the clinical decision to offer surgery on the history and clinical examination findings.

There has been considerable interest in the measurement of visual disability as a basis for a decision to offer cataract surgery. Estimates of visual disability include the effects of cataract on lifestyle and activities of daily living, history of falls, caring responsibilities and need to continue driving or working. A number of tools for estimating visual disability caused by cataract have been published; $27-32$ however, none have yet been validated for use in UK populations and further research is needed before they can be recommended for routine use.

\section{Recommended high-quality cataract care pathway} A high-quality cataract care pathway should provide equity of access based on the needs of individual patients. An exemplar care pathway for cataract surgery has previously been published by the NHS Institute for Innovation and Improvement. ${ }^{33}$ Treatment pathways must be personalised to the patient and adaptable for patients with specific needs. For example $4-5 \%$ of patients undergoing cataract surgery require general anaesthesia. ${ }^{7,21}$ Although cataract surgery is generally safe, the risk of operative complications and a poor visual outcome can vary by 10 -fold or more depending on the presence of a range of common ocular and systemic risk factors; ${ }^{34}$ therefore, it is important that the final decision to operate and individualised planning of care is undertaken by the cataract surgical team. Appropriate provision should be made for intraoperative and postoperative complications which may occasionally arise. The cataract surgery care pathway should support high-quality training and continuing professional development of the professionals who contribute to it.

\section{Quality dashboard for cataract surgery}

Providers of cataract care should be able to supply data on surgical outcomes to allow monitoring of the clinical care provided. In cataract services where community Optometrists are contracted to undertake the final postoperative assessment, there should be a mechanism for feedback of visual and refractive outcome data and patient satisfaction to the surgical team. For aspects of care where continuous audit is not practical, periodic sampling audit may be indicated.

The benchmark data in Table 1 are derived from large case series and summarise the mean and distribution of significant complications of cataract surgery, visual and refractive outcomes.

These outcomes are influenced by case-mix and, therefore, figures, which appear to deviate significantly or persistently from the mean do not therefore necessarily indicate a cause for concern, but should prompt further analysis. Posterior capsule rupture (PCR) during cataract surgery has been shown to be the only modifiable risk factor for a poor visual outcome ${ }^{34}$ and the occurrence of PCR is associated with increasing age, male sex, diabetic retinopathy, glaucoma, longer axial length, advanced cataract and trainee surgeons. ${ }^{36}$

\section{Patient reported outcome measures (PROMs)}

There is currently no widely validated PROM for cataract surgery. Based on a systematic review and study of cataract PROMs, the Catquest-9SF questionnaire currently appears to be the most promising instrument. ${ }^{37,38} \mathrm{~A}$ National Institute for Health Research (NIHR) applied cataract research programme is currently funded to develop a cataract PROM suitable for use in the NHS. ${ }^{39}$

\section{New devices and techniques in cataract surgery} Phacoemulsification is the standard surgical technique used in over $99.7 \%$ cataract operations ${ }^{21}$ with implantation of a monofocal intraocular lens. Some providers may offer variants although there is no additional NHS tariff for these.

\section{(i) Toric intraocular lens}

A systematic review found that toric intraocular lenses result in increased unaided distance visual acuity. ${ }^{40}$

\section{(ii) Multifocal and accommodating intraocular lens}

A Cochrane review concluded that multifocal IOLs were effective at improving near vision without any adverse effect on distance visual acuity. However there was an associated reduction in contrast sensitivity and increased risk of perception of halos. ${ }^{41}$ NICE guidance recommends special arrangements for patient selection, preoperative counselling and consent beyond that required for monofocal IOLs. ${ }^{42,43}$

Table 1 Quality dashboard for cataract surgery: mean complication rates and outcomes

\begin{tabular}{ll}
\hline Parameter & Mean or value from large case series \\
\hline $\begin{array}{l}\text { Overall mean rate of posterior capsule tear and/or vitreous } \operatorname{loss}^{\mathrm{a}} \\
\text { Rate of endophthalmitis }\end{array}$ & $\begin{array}{l}1.9 \text { to } 2.0^{7,21} \\
\text { Proportion achieving 6/12 or better best measured (no pre-existing }\end{array}$ \\
$\begin{array}{l}\text { ocular co-pathology) } \\
\text { Proportion achieving 6/12 or better best measured (with pre-existing }\end{array}$ & $95 \% \%^{7,21}$ \\
$\begin{array}{l}\text { ocular co-pathology) } \\
\text { Proportion achieving } 6 / 6 \text { best measured (no pre-existing ocular co-pathology) }\end{array}$ & $80 \%, 7,21$ \\
Proportion achieving $6 / 6$ best measured (with pre-existing ocular co-pathology) & $51 \% \%^{7,21}$ \\
\hline
\end{tabular}

\footnotetext{
${ }^{a}$ Posterior capsule tear rates will vary with the proportion of patients with ocular copathology.
} 
(iii) Laser-assisted cataract surgery

Lasers can automate some of the steps of cataract surgery with greater precision and consistency than can be achieved by a surgeon. The conclusions from an earlier NIHR Horizon Scanning Centre briefing are still valid, namely further research is needed to determine the effectiveness and long-term safety profile of laser-assisted cataract surgery compared with current techniques. ${ }^{44}$

\section{Summary}

- The presence of cataract causes disability and increases the likelihood that individuals will suffer adverse events such as falls.

- Cataract surgery is the only effective intervention to treat cataracts and is cost effective.

- Until better measures have been validated, simple thresholds for surgery based on symptoms and visual acuity as described in the document provide a reasonable basis on which to offer surgery for the majority of patients.

- Where an individual has cataract in both eyes, cataract surgery should be offered for both eyes.

- Cataract surgery care pathways must be personalised to the patient and adaptable for patients with specific needs.

- The risk of a poor outcome from cataract surgery is generally low but can be increased substantially by a range of systemic and ocular risk factors, many of which can be mitigated by careful preoperative planning.

- Outcome measures of cataract surgery such as visual acuity, accuracy of refractive correction, occurrence of significant operative and postoperative complications should be recorded routinely. The data should be available to care providers and commissioners.

- Commissioning of cataract care should encompass the whole cataract care pathway from initial assessment and treatment planning to final postoperative review.

\section{Funding statement}

The development of the Cataract Surgery Commissioning Guidance was funded by the Royal College of Ophthalmologists and the Nottingham University Hospitals Trust (under $£ 10000$ ).

\section{Conflict of interest}

The authors declare the following conflict of interests: The Royal National Institute for Blind People receives money from pharmaceutical companies in the form of educational grants. In recent years, it has been supported by Novartis, Allergan, Alcon and Bayer for initiatives such as the provision of Eye Clinic Liaison Officers in eye clinics. The funding is declared in the RNIB's annual report, and each year the support given by

pharmaceutical companies represents $<1 \%$ of its overall funding. Ms Sophie Coronini-Cronberg is a Consultant in Public Health at BUPA. Alex Day and Richard Wormald were supported by the National Institute for Health Research (NIHR) Biomedical Research Centre based at Moorfields Eye Hospital NHS Foundation Trust and UCL Institute of Ophthalmology.

\section{Acknowledgements}

The guideline development group wish to acknowledge Ms Iris Gordon of the Cochrane Eyes and Vision Group, and the London School of Hygiene and Tropical Medicine for additional literature searches.

\section{Disclaimer}

The views expressed are those of the author(s) and not necessarily those of the NHS, the NIHR or the Department of Health.

\section{Members of the Royal College of Ophthalmologists Cataract Surgery Commissioning Guidance Development Group}

Richard Smith (Chair), Kamal Bishai, Sophie CoroniniCronberg, Nicholas Cook, Alex Day, Deborah Dow, Clara Eaglen, Veronica Fergusson, Anne Gilvarry, Mohit Gupta, Rea Mattock, Gillian Rudduck, Mary Shaw, John M Sparrow, Nicholas Wilson-Holt, Richard Wormald and Katrina Venerus.

\section{References}

1 The Royal College of Ophthalmologists 2015. Commissioning Guide: Cataract Surgery, 2015. Available at: https:www.rcophth.ac.uk/wp-content/uploads/2015/03/ Commissioning-Guide-Cataract-Surgery-Final-February2015.pdf (accessed on 1 November 2015).

2 Coronini-Cronberg S, Lee H, Darzi A, Smith P. Evaluation of clinical threshold policies for cataract surgery among English commissioners. J Health Serv Res Policy 2012; 17: 241-247.

3 Royal National Institute for the Blind. Surgery deferred. Sight denied. Variation in cataract surgery provision across England, 2013. Available at: https://www.rnib.org.uk/ sites/default/files/Surgery\%20deferred\%20sight\%20denied $\% 20$ Campaign\%20report.pdf (accessed on 1 June 2014).

4 The NHS Atlas of Variation 2010. Map 12, 2011. Available at: http:/ / www.rightcare.nhs.uk/atlas/qipp_nhsAtlas-LOW_ 261110c.pdf (accessed on 1 June 2014).

5 The Royal College of Ophthalmologists. Commissioning Guidance Process Manual. The Royal College of Ophthalmologists: London, UK, 2013.

6 Bourne RR, Stevens GA, White RA, Smith JL, Flaxman SR, Price $\mathrm{H}$ et al. Causes of vision loss worldwide, 1990-2010: a systematic analysis. Lancet Global Health 2013; 1: e339-e349.

7 Day AC, Donachie PHJ, Sparrow JM, Johnston RL. The Royal College of Ophthalmologists' National Ophthalmology Database study of cataract surgery: report 1, visual outcomes and complications. Eye (Lond) 2015; 29: 552-560. 
8 Minassian DC, Reidy A. Future Sight Loss UK (2): An epidemiologic and economic model for sight loss in the decade 2010-2020, 2009. Available at: http://www.rnib.org uk/sites/default/files/FSUK_2.pdf (accessed on 6 January 2014).

9 Health \& Social Care Information Centre. Hospital Episode Statistics, 2011. Available at: http://www.hscic. gov.uk/hes (accessed on 22 February 2014).

10 Office for National Statistics. 2011 Census, Population and Household Estimates for the United Kingdom. 2010. Available at: http:/ /www.ons.gov.uk/ (accessed on 20 November 2013).

11 The Royal College of Ophthalmologists. Cataract Surgery Guidelines, 2010. Available at: http://www.rcophth.ac.uk (accessed on 17 October 2013).

12 Rauf A, Malik R, Bunce C, Wormald R. The British Asian community eye study: outline of results on the prevalence of eye disease in British Asians with origins from the Indian subcontinent. Indian J Ophthalmol 2013; 61: 53-58.

13 Gillespie LD, Robertson MC, Gillespie WJ, Sherrington C, Gates S, Clemson LM et al. Interventions for preventing falls in older people living in the community. Cochrane Database Syst Rev 2012; (9): CD007146.

14 Harwood RH, Foss AJ, Osborn F, Gregson RM, Zaman A, Masud T. Falls and health status in elderly women following first eye cataract surgery: a randomised controlled trial. Br J Ophthalmol 2005; 89: 53-59.

15 Hodge W, Horsley T, Albiani D, Baryla J, Belliveau M, Buhrmann $\mathrm{R}$ et al. The consequences of waiting for cataract surgery: a systematic review. CMAJ 2007; 176: 1285-1290.

16 Busbee BG, Brown MM, Brown GC, Sharma S. Cost-utility analysis of cataract surgery in the second eye. Ophthalmology 2003; 110: 2310-2317.

17 Hiratsuka Y, Yamada M, Murakami A, Okada AA, Yamashita $\mathrm{H}$, Ohashi $\mathrm{Y}$ et al. Cost-effectiveness of cataract surgery in Japan. Jpn J Ophthalmol 2011; 55: 333-342.

18 Lansingh VC, Carter MJ, Martens M. Global costeffectiveness of cataract surgery. Ophthalmology 2007; 114: 1670-1678.

19 Lansingh VC, Carter MJ. Use of Global Visual Acuity Data in a time trade-off approach to calculate the cost utility of cataract surgery. Arch Ophthalmol 2009; 127: 1183-1193.

20 Sach TH, Foss AJ, Gregson RM, Zaman A, Osborn F, Masud T et al. Falls and health status in elderly women following first eye cataract surgery: an economic evaluation conducted alongside a randomised controlled trial. Br J Ophthalmol 2007; 91: 1675-1679.

21 Jaycock P, Johnston RL, Taylor H, Adams M, Tole DM, Galloway $\mathrm{P}$ et al. The Cataract National Dataset electronic multi-centre audit of 55567 operations: updating benchmark standards of care in the United Kingdom and internationally. Eye (Lond) 2009; 23: 38-49.

22 Frampton G, Harris P, Cooper K, Lotery A, Shepherd J. The clinical effectiveness and cost-effectiveness of secondeye cataract surgery: a systematic review and economic evaluation. Health Technol Assess 2014; 18: 1-205.

23 Lundström M, Brege KG, Florén I, Stenevi U, Thorburn W. Impaired visual function after cataract surgery assessed using the Catquest questionnaire. J Cataract Refract Surg 2000; 26: 101-108.

24 Minassian D, Reidy A, Desai P, Farrow S, Vafidis G, Minassian A. The deficit in cataract surgery in England and Wales and the escalating problem of visual impairment: epidemiological modelling of the population dynamics of cataract. Br J Ophthalmol 2000; 84: 4-8.

25 Desai P. Cataract surgery: one or both eyes? Br J Ophthalmol 2012; 2012: 301733.

26 Lundström M, Barry P, Henry Y, Rosen P, Stenevi U. Visual outcome of cataract surgery; study from the European Registry of Quality Outcomes for Cataract and Refractive Surgery. J Cataract Refract Surg 2013; 39: 673-679.

27 Hadorn DC, Holmes AC. The New Zealand priority criteria project. Part 1: Overview. BMJ 1997; 314: 131-134.

28 Romanchuk KG, Sanmugasunderam S, Hadorn DCSteering Committee of the Western Canada Waiting List Project. Developing cataract surgery priority criteria: results from the Western Canada Waiting List Project. Can J Ophthalmol 2002; 37: $145-154$.

29 Allepuz A, Espallargues M, Moharra M, Comas M, Pons JMResearch Group on Support Instruments - IRYSS Network. Prioritisation of patients on waiting lists for hip and knee arthroplasties and cataract surgery: Instruments validation. BMC Health Serv Res 2008; 8: 76.

30 Quintana JM, Espallargues M, Las Hayas C, Allepuz A, Vrotsou K, Moharra M et al. Comparison of 3 systems for assigning priority to patients on waiting lists for cataract extraction. Can J Ophthalmol 2010; 45: 125-131.

$31 \mathrm{Ng} \mathrm{JQ}$, Lundström M. Impact of a National system for waitlist prioritization: the experience with NIKE and cataract surgery in Sweden. Acta Ophthalmol 2013; 92: 378-381.

32 Lundström M, Albrecht S, Håkansson I, Lorefors R, Ohlsson S, Polland W et al. NIKE: a new clinical tool for establishing levels of indications for cataract surgery. Acta Ophthalmol Scand 2006; 84: 495-501.

33 NHS Institute for Innovation and Improvement. Focus on: cataracts. Delivering quality and value 2008. Available at: http://www.institute.nhs.uk (accessed on 14 February 2014).

34 Sparrow JM, Taylor H, Qureshi K, Smith R, Birnie K, Johnston RL et al. The Cataract National Dataset electronic multi-centre audit of 55,567 operations: risk indicators for monocular visual acuity outcomes. Eye (Lond) 2012; 26: 821-826.

35 Endophthalmitis Study Group, European Society of Cataract \& Refractive Surgeons. Prophylaxis of postoperative endophthalmitis following cataract surgery: results of the ESCRS multicenter study and identification of risk factors. J Cataract Refract Surg 2007; 33: 978-988.

36 Narendran N, Jaycock P, Johnston RL, Taylor H, Adams M, Tole DM et al. The Cataract National Dataset electronic multicentre audit of 55,567 operations: risk stratification for posterior capsule rupture and vitreous loss. Eye 2009; 23: 31-37.

37 Lundström M, Pesudovs K. Questionnaires for measuring cataract surgery outcomes. J Cataract Refract Surg 2011; 37: 945-959.

38 McAlinden C, Gothwal VK, Khadka J, Wright TA, Lamoureux EL, Pesudovs K. A head-to-head comparison of 16 cataract surgery outcome questionnaires. Ophthalmology 2011; 118: 2374-2381.

39 Sparrow JM Measuring visual disability due to cataract: development of a cataract patientreported outcome measure (Cat-PROM) - V2. Available at: http://public.ukcrn.org.uk/ search/StudyDetail.aspx?StudyID=15931 (accessed on 22 February 2014).

40 Agresta B, Knorz MC, Donatti C, Jackson D. Visual acuity improvements after implantation of toric intraocular lenses 
in cataract patients with astigmatism: a systematic review. BMC Ophthalmol 2012; 12: 41.

41 Calladine D, Evans JR, Shah S, Leyland M. Multifocal versus monofocal intraocular lenses after cataract extraction. Cochrane Database Syst Rev 2012; (9): CD003169.

42 NICE. Implantation of multifocal (non-accommodative) intraocular lenses during cataract surgery. Interventional Procedure Guidance 264. NICE 2008. Available at: http:// www.nice.org.uk/ (accessed on 20 November 2013).

43 NICE. Implantation of accommodating intraocular lenses for cataract. NICE 2007. Available at: http:/ /www.nice.org.uk/ (accessed on 1 April 2014).

44 NIHR Horizon Scanning Centre. Femtosecond lasers for cataract surgery 2012. Available at: http:/ /www.hsc.nihr.ac. $\mathrm{uk} /$ topics/femtosecond-lasers-for-cataract-surgery/ (accessed on 20 November 2014).

AC Day ${ }^{1,2,3}$, R Wormald ${ }^{1,2,3}$, S Coronini-Cronberg ${ }^{4,5}$, R Smith ${ }^{6}$ and the Royal College of Ophthalmologists Cataract Surgery Commissioning Guidance Development Group 7
${ }^{1}$ Moorfields Eye Hospital, London, UK

${ }^{2}$ The NIHR Biomedical Research Centre at Moorfields Eye Hospital NHS Foundation Trust and UCL Institute of Ophthalmology, London, UK

${ }^{3}$ UCL Institute of Ophthalmology, London, UK

${ }^{4}$ Department of Primary Care and Public Health, Faculty of Medicine, Imperial College, London, UK

${ }^{5}$ Public Health, and Head of Clinical Effectiveness, BUPA, London, UK

${ }^{6}$ Buckinghamshire Healthcare NHS Trust,

Buckinghamshire, UK

E-mail: richard.smith@doctors.org.uk

${ }^{7}$ Members of the Royal College of Ophthalmologists Cataract Surgery Commissioning Guidance Development Group are listed before the references.

Eye (2016) 30, 498-502; doi:10.1038/eye.2015.271;

published online 22 January 2016 